\title{
Precarização do vínculo de trabalho do médico na Paraíba: reflexos éticos
}

Bruno Leandro de Souza ${ }^{1}$, Thiago Guimarães Pereira Souza ${ }^{2}$, Caio Chaves de Holanda Limeira ${ }^{3}$, Heloisa Calegari Borges ${ }^{3}$, Naraiana Chaves Pereira ${ }^{3}$

1. Faculdade de Medicina do Porto, Porto, Portugal. 2. Faculdades Nova Esperança, João Pessoa/PB, Brasil.

3. Universidade Potiguar, Natal/RN, Brasil.

\section{Resumo}

Observa-se no Brasil uma crescente precarização dos serviços públicos e do trabalho médico. Na Paraíba, há uma forma peculiar de contratação, denominada "codificação". Trata-se de um vínculo inconstitucional, estabelecido sem assinatura de contrato, por meio do qual o médico recebe por produção e sem garantia de direitos. O objetivo do presente artigo é discutir a precarização do trabalho médico no estado da Paraíba por meio da codificação e suas implicações bioéticas. O texto traz resultados de análise de dados disponíveis no Portal da Transparência do Tribunal de Contas do Estado. Os dados revelam que, no momento da pesquisa, 1.474 médicos trabalhavam na rede estadual de saúde, sendo $716(48,6 \%)$ concursados e $758(51,4 \%)$ codificados. Dentre os codificados, 55,8\% são homens ( $p=0,001)$, 67,1\% trabalham na Zona da Mata Paraibana $(p=0,021)$, e mais de um terço presta serviços para o estado como clínicos. Conclui-se que a codificação é uma forma ilegal de contratação, e que é preciso resgatar o valor social do médico e a dignidade humana, para que a estabilidade desses trabalhadores e a formação de vínculo com os usuários não sejam prejudicadas. Palavras-chave: Emprego. Médicos. Trabalho.

\section{Resumen}

\section{Precarización del vínculo laboral del médico en Paraíba: reflejos éticos}

En Brasil existe una precariedad creciente de los servicios públicos, así como del trabajo médico. En Paraíba hay una forma contractual peculiar llamada "codificación", un vínculo inconstitucional establecido sin un contrato firmado en el que el médico recibe para la producción sin garantía de derechos. Este artículo propone discutir la precariedad del trabajo del médico en el estado de Paraíba mediante la codificación y sus implicaciones bioéticas. Este es un estudio transversal con análisis de datos del portal de transparencia del Tribunal de Cuentas del Estado sobre detalles de médicos codificados. De los 1.474 médicos que trabajan en la red de salud del estado, $716(48,6 \%)$ son reclutados públicamente y $758(51,4 \%)$ están codificados. Fue significativo que el $55,8 \%$ son hombres $(p=0,001>)$ y el $67,1 \%$ trabaja en la Zona da Mata Paraibana $(p=0,021)$. Más de un tercio están codificados como clínicos. Se concluye que la codificación es una forma ilegal de contratación y que el rescate del valor social del médico y la dignidad humana es esencial para que no haya interferencia en la estabilidad de estos trabajadores y en la formación de vínculos con los usuarios.

Palabras clave: Empleo. Médicos. Trabajo.

\section{Abstract \\ Precariousness of medical work in Paraíba: ethical impacts}

Brazil faces an increasing precariousness in public services, as well as in medical work. Paraíba has a peculiar contracting modality called "codification", an unconstitutional employment relationship established without a signed contract, in which the physicians is paid for service provision without guarantee of labor rights. This arcticle discusses the precariousness of medical work in the State of Paraíba by examining the codification system and its bioethical implications. This is a cross-sectional study with data from the transparency portal of the State Court of Accounts on codified physicians. Results show that 1,474 physicians work in the state health care system, 716 (48.6\%) of whom were hired through public entrance examinations and $758(51.4 \%)$ by codification. Significantly, $55.8 \%$ of codified physicians are men $(p=0.001)$ and $67.1 \%$ work in Paraíba's Zona da Mata region $(p=0.021)$. More than a third is registered as clinicians. Recognizing the social value of the physician is essential to prevent negative impacts on job stability and on the formation of bonds between workers and users. We must re-establish human dignity in this context. Keywords: Employment. Physicians. Work.

\footnotetext{
Declaram não haver conflito de interesse.
} 
Conforme a Declaração dos Direitos Humanos de 1948, em seu artigo 25, todo ser humano tem direito a um padrão de vida que assegure a si e a sua família saúde e bem-estar, incluindo alimentação, vestuário, habitação, cuidados médicos e serviços sociais indispensáveis ${ }^{1}$. 0 direito à saúde, de forma ampla, abrange não só o atendimento em hospitais ou em unidades básicas, mas também a qualidade de vida associada a outros direitos básicos, como educação e saneamento básico, com ações preventivas. A saúde, portanto, vincula-se ao direito de todo ser humano a uma vida digna.

A saúde é direito de todos e dever do Estado, garantido mediante políticas sociais e econômicas que visam reduzir o risco de doenças e outros agravos e garantir acesso universal e igualitário a ações e serviços para promover, proteger e recuperar a saúde (art. 196 da Constituição Federal brasileira) ${ }^{2}$. Assim, cabe ao poder público, nos termos da lei, regulamentar, fiscalizar e controlar essas ações e serviços, seja diretamente ou por meio de terceiros, por pessoa física ou jurídica de direito privado (art. 197 da Constituição) ${ }^{2}$.

A política de saúde no Brasil é reflexo de processos históricos, sociais, econômicos e políticos. Entender tais processos é fundamental para compreender o Sistema Único de Saúde (SUS). O sistema brasileiro, embora único, integra uma rede regionalizada e hierarquizada que tem como diretrizes: a descentralização, com direção única em cada esfera de governo; atendimento integral, com prioridade a atividades preventivas, sem prejuízo dos serviços assistenciais; e participação da comunidade (art. 198 da Constituição) ${ }^{2}$.

Contudo, apesar do ideal de excelência, na prática, a prestação de serviços à comunidade ainda está muito abaixo das expectativas e necessidades da população brasileira. O direito universal e igualitário à saúde sempre esteve em risco devido ao subfinanciamento ${ }^{3}$. A precarização dos serviços públicos apresenta-se de diversas formas: grandes vazios assistenciais, deficiência na infraestrutura, falta de insumos e equipamentos, terceirização da mão de obra, problemas de gestão e de gerenciamento dos processos, insuficiência de concursos públicos, déficit de pessoal e instabilidade nos vínculos trabalhistas ${ }^{3}$.

É importante destacar, dentre esses vários aspectos do sucateamento dos serviços públicos, a precarização dos vínculos trabalhistas na área da saúde. Segundo Sousa e colaboradores ${ }^{4}$, estudar os sistemas de remuneração e contratação do trabalho médico é importante para formular políticas públicas no setor da saúde. De fato, a opção por um ou outro método de contratação e pagamento dos médicos - seja por meio de trabalho assalariado ou contratação/credenciamento com remuneração por procedimento, ou ainda pela combinação desses dois métodos é estratégica para a gestão de sistemas de saúde. Tal escolha tem impacto direto na qualidade dos serviços prestados à população e no grau de universalidade e equidade de acesso ${ }^{3}$.

Nas últimas décadas, o médico, importante agente do SUS, teve de se adaptar à nova ordem, acolhendo estruturalmente a dinâmica de organização e funcionamento do tomador de serviço, submetendo-se às mesmas condições dos demais trabalhadores no sistema capitalista moderno: instabilidade, ritmo intenso, jornadas de trabalho prolongadas, redução da remuneração e perda do controle da atividade ${ }^{3}$.

Para o direito brasileiro, o trabalho prestado de forma transitória ou ocasional, ainda que subordinado, não garante a seu executor os benefícios decorrentes da relação de emprego, tanto que o artigo $3^{\circ}$ da Consolidação das Leis do Trabalho (CLT) dispõe que só é empregado quem presta serviços de natureza não eventual ${ }^{5}$. A relação de emprego é uma relação de trabalho qualificada, em que há vínculo jurídico. Para configurá-la, deverão estar presentes, cumulativamente: o trabalho prestado por uma pessoa física, pessoalmente, onerado, habitual ou não eventual e subordinado ${ }^{6}$. Sem algum desses requisitos, deixa-se de ter uma relação de emprego e passa-se a ter uma prestação de serviço. Assim, a relação de trabalho seria um gênero de que a relação de emprego é uma espécie ${ }^{6}$.

A vinculação formal dos médicos às organizações de saúde, principalmente as hospitalares, assume variadas formas em diferentes países. Há desde a integração vertical - condição de pessoa física, assalariada, contratada diretamente pelo hospital por tempo indeterminado até a condição de autônomo, prestador eventual de serviços sob contratos pontuais, passando ainda por formas intermediárias, mais ou menos "frouxas", de vinculação de médicos como 
pessoas físicas ou jurídicas, sob contratos mais ou menos longos, com ou sem exclusividade ${ }^{3}$.

Tem sido uma prática comum nos hospitais e clínicas descaracterizar dois elementos que configuram a relação de emprego - a pessoalidade e a subordinação - por meio da contratação do médico como pessoa jurídica (expediente conhecido na doutrina trabalhista como "pejotização"). Essa exigência de contratação do empregado por meio de pessoa jurídica individual ou como prestador de serviços tem o intuito de camuflar a relação de emprego existente.

Os profissionais contratados sob essa forma enfrentam grandes dificuldades de sindicalização e de união para reivindicar direitos e impedir possíveis abusos por parte dos contratantes. Tal modalidade de contratação, na forma como vem sendo implementada, caracteriza mais uma maneira de precarização da atividade médica, uma vez que se trata de sociedade fictícias, operadas unicamente com a finalidade de burlar o contrato de trabalho ${ }^{7}$.

Outra forma inadequada de mão de obra médica, no que concerne ao critério da onerosidade, é a contratação por meio de cooperativas. O cooperativismo é um eficiente e justo distribuidor de rendas, pois elimina a intermediação, proporciona autonomia de trabalho e dá mais segurança ao trabalhador associado. Todavia, na realidade laborativa dos médicos, constatam-se situações de fraude: não observação dos princípios que regem o cooperativismo, ausência de características essenciais que deveriam revestir a legítima cooperativa e, finalmente, a presença de elementos que configuram uma relação de emprego ${ }^{8}$.

É relevante destacar aqui, antes de detalhar o caso da Paraíba, o artigo 37 da Constituição da República Federativa do Brasil, que é cristalino ao afirmar que a administração pública direta $e$ indireta de qualquer dos Poderes da União, dos Estados, do Distrito Federal e dos Municípios devem obedecer aos princípios de legalidade, impessoalidade, moralidade, publicidade e eficiência ${ }^{2}$. Cabe esclarecer ainda, conforme o parágrafo II do mesmo artigo, que $a$ investidura em cargo ou emprego público depende de aprovação prévia em concurso público de provas ou de provas e títulos, de acordo com a natureza e a complexidade do cargo ou emprego, na forma prevista em lei, ressalvadas as nomeações para cargo em comissão declarado em lei de livre nomeação e exoneração ${ }^{2}$.

Portanto, a contratação para serviços públicos, como prevista pela Carta Magna, deve ser por concurso público ou processo seletivo. As exceções, previstas nos artigo 37, inciso IX, são as contratações por tempo determinado hipótese em que a Lei 8.745/1993 ${ }^{9}$ estabelece os casos permitidos de contratação para atender a necessidade temporária de excepcional interesse público - e os cargos em comissão, de livre nomeação e exoneração. Nesse sentido, já decidiu o Tribunal Superior do Trabalho que $a$ contratação de servidor público, após a CF/88, sem prévia aprovação em concurso público, encontra óbice no respectivo art. $37, \|$ e $\S 2^{\circ}$, somente the conferindo direito ao pagamento da contraprestação pactuada, em relação ao número de horas trabalhadas, respeitado o valor da hora do salário mínimo, e dos valores referentes aos depósitos do FGTS ${ }^{10}$.

No estado do Paraíba, uma modalidade não prevista na legislação brasileira foi criada junto ao ente público. Essa modalidade foi denominada "codificação".

\section{Regionalização no estado da Paraíba}

O estado da Paraíba tem aproximadamente $56.470 \mathrm{~km}^{2}$ de extensão e uma população de 3,996 milhões de habitantes, segundo estimativas de 2018 do Instituto Brasileiro de Geografia e Estatística (IBGE) ${ }^{11}$. Dados do Conselho Regional de Medicina da Paraíba (CRM-PB) apontam que havia no estado, em maio de 2019, 7.984 profissionais inscritos e habilitados para a atividade médica. A razão de médico por habitante, portanto, é de 2 para 1.000, ou seja, o dobro do mínimo parametrizado pela Organização Mundial da Saúde ${ }^{12}$.

A Paraíba é dividida administrativamente em quatro mesorregiões - Zona da Mata Paraibana, Borborema, Agreste e Sertão Paraibano -, distintas entre si em relação a características sociodemográficas e problemas de saúde. Essa divisão facilita o planejamento de serviços de atenção primária, psicossocial, especializada e hospitalar, urgência e emergência e vigilância em saúde - ações e 
serviços que fazem parte das linhas de cuidados do SUS. A tomada de decisões na assistência à saúde pode ser mais assertiva com o amplo conhecimento da realidade regional ${ }^{13}$.

O Plano de Saúde do Estado (2016-2019), aprovado pelo Conselho Estadual de Saúde, expõe as desigualdades mesorregionais. Observa-se concentração de médicos e da oferta de serviços sobretudo na Zona da Mata Paraibana, onde está localizada a capital do estado. Segundo dados do CRM-PB, 52\% do total de médicos inscritos na Paraíba trabalham na região metropolitana de João Pessoa ${ }^{13}$.

\section{"Codificação" e precarização do trabalho médico na Paraíba}

Há mais de 10 anos, o governo estadual da Paraíba condiciona a "contratação" de médicos e outros profissionais de saúde a um método inconstitucional, de conhecimento amplo e público, denominado "codificação" ${ }^{14}$. É importante ressaltar que não se trata de contratação para atender a necessidade temporária de excepcional interesse público, nem de cargos em comissão, de livre nomeação e exoneração, nem mesmo de contratação por meio de pessoa jurídica. Tampouco esse modelo de contratação alcança características suficientes para que possam fazer analogias com modalidades já previstas no ordenamento jurídico ${ }^{14}$.

Na modalidade de codificação, de início caracterizada como temporária e por excecional interesse público, a admissão ocorre sem seleção prévia e sem que nenhum contrato seja assinado ${ }^{14}$. Por um compromisso "apalavrado" ou contrato verbal, o médico recebe um "código", que funcionaria como uma espécie de matrícula. A partir do momento em que o profissional inicia suas atividades laborativas, a unidade informa a Secretaria Estadual de Saúde, que deposita os honorários de acordo com o número de plantões ou atividades. O pagamento é realizado em conta bancária informada pelo profissional no mês subsequente ao trabalhado. Não há descontos previdenciários, e o profissional não goza de direitos fundamentais, como férias, $13^{\circ}$ salário e abono por falta justificada ou óbito de parente em primeiro grau ${ }^{14}$.
Não há registro oficial de quando a codificação foi instituída como forma de suprir emergencialmente a carência de profissionais nos serviços públicos estaduais. O motivo é que uma política ilegal não pode ser oficializada. Porém, há relatos de que a prática ocorra há pelo menos 12 anos sob essa denominação. Desde então, a Paraíba já foi administrada por quatro governadores de três partidos políticos diferentes. Trata-se, portanto, de uma política de Estado, e não de governo, embora ilegal ${ }^{14}$.

Antes da codificação, já havia outra modalidade de precarização que adotava o sistema de pagamento de honorários por produtividade, por meio de informação e comprovação do número do Cadastro de Pessoa Física, diretamente no caixa de agências bancárias. $O$ código teria sido criado como forma de aperfeiçoar a prática, garantindo melhor controle. Diversas matérias jornalísticas e declarações dos próprios gestores confirmam o fato.

Para tentar minimizar o impacto da ilegalidade, o Tribunal de Contas do Estado (TCE) tem disponibilizado mensalmente, no banco de dados do Sistema de Acompanhamento da Gestão dos Recursos da Sociedade (Sagres), o nome, os salários e a lotação de todos os codificados, assim como acontece com profissionais concursados ${ }^{15}$. A grande diferença é que, no caso dos codificados, permanece a ilegalidade na contratação.

Para o STF, às contratações irregulares, sem concurso público, pode se aplicar a teoria do funcionário de fato, sendo válidos os atos praticados pelo agente, ainda que a situação tenha aparência de legalidade ${ }^{16}$. Outrossim, há inquérito aberto pelo Ministério Público Federal para investigar possíveis irregularidades em pagamento de servidores com recursos destinados à saúde (Procedimento Preparatório 1.24.000.001214/2017-62) ${ }^{17}$.

\section{Relação médico-estado e precarização do trabalho}

O médico e outros funcionários da saúde passaram a trabalhar rotineiramente no serviço público sem a estabilidade garantida pela Lei 8.112/1990. Segundo o artigo 22 dessa lei, 
o servidor, após período probatório, só perderá o cargo em virtude de sentença judicial transitada em julgado ou de processo administrativo disciplinar no qual the seja assegurada ampla defesa ${ }^{18}$. Já o médico, na modalidade de codificado, pode ser demitido independentemente de causa e a qualquer momento.

Além disso, a prática tornou-se especialmente útil para que governos justificassem gastos como pagamentos de serviços, e não como pagamentos de pessoas, produzindo a impressão de cumprimento da Lei Complementar 100/2000 ${ }^{19}$, a Lei de Responsabilidade Fiscal (LRF). O estado da Paraíba, em 2018, apresentou 60,3\% da Receita Corrente Líquida como voltada a gastos com pessoal. Segundo a LRF, o limite é de $60 \%$, de modo que o governo argumenta não mais suportar contratar médicos por concurso público.

Há médicos que veem a codificação como forma de ocultar acúmulos de cargos, pois muitos que se submetem a essa condição não têm seu nome inscrito no Cadastro Nacional de Estabelecimento de Saúde ${ }^{14}$. No entanto, de acordo com o artigo 37, inciso XVI da Constituição Federal, não se permitem três vínculos públicos para qualquer que seja o profissional. Para o médico que já tem dois vínculos públicos, a codificação pode ser uma forma de manter um terceiro emprego em serviço público ${ }^{2}$. Ainda soma-se a essa ilegalidade, como já mencionado, a ausência de direitos trabalhistas.

A grande diversidade de formas de contratação reflete interesses e estratégias - nem sempre coincidentes - de médicos, hospitais, governos e terceiros pagadores. Além das restrições legais, são levadas em consideração "conveniências" tributário-fiscais, tipos de compartilhamento de riscos econômicos e morais e grau de exclusividade na relação entre as partes ${ }^{3}$.

Nesse contexto, é imprescindível um esforço extra para repensar - dentro de um processo mais global de adequação das relações de trabalho e de vinculação estratégica dos profissionais - novos regimes remuneratórios e contratuais, que venham, dentro de limites orçamentários sustentáveis, maximizar a produtividade, melhorar a qualidade dos serviços e assegurar níveis adequados de cooperação entre trabalho e gerência e entre profissionais de saúde ${ }^{3}$.

\section{Método}

O estudo visa discutir as implicações bioéticas da precarização do trabalho médico no estado da Paraíba por meio de modalidade de contratação denominada "codificação". Trata-se de pesquisa inédita sobre o tema, documental, transversal, de caráter descritivo e exploratório, com abordagem quantitativa. A amostra do estudo foi formada por médicos do estado da Paraíba contratados por codificação e ativos entre dezembro de 2018 e novembro de 2019.

Para levantar o número de médicos codificados, seus honorários e o número de substituições e contratações realizadas, a pesquisa analisou o banco de dados, denominado Sagres, do Portal da Transparência do TCE da Paraíba ${ }^{15}$. Todas as cidades com serviço de saúde mantido pelo governo estadual foram incluídas. As unidades geridas por organizações sociais, que têm regime de contratação de acordo com a CLT, foram desconsideradas.

Os registros foram categorizados por gênero, mesorregião e especialidade e organizados em tabelas de contingência, apresentadas por meio de frequências simples e relativas. $O$ teste de qui-quadrado foi usado para testar associações entre variáveis categóricas e o burnout. As análises foram feitas usando o software SPSS versão 20.0.0.0, considerando uma significância de 0,05.

$\mathrm{O}$ estudo considerou as normas de pesquisa envolvendo seres humanos, de acordo com a Resolução 466/2012 do Conselho Nacional de Saúde ${ }^{20}$. Foram observados os princípios básicos da bioética: autonomia, não maleficência, beneficência e justiça. Os dados utilizados foram colhidos de fonte pública e, por serem secundários, dispensaram aplicação de termo consentimento livre e esclarecido e análise de Comitê de Ética em Pesquisa.

\section{Resultados e discussão}

Em novembro de 2019, 7.984 médicos estavam registrados no Conselho Regional de Medicina e aptos a exercer a profissão. Destes, 1.474 trabalhavam na rede estadual de saúde, sendo 716 concursados e 758 codificados. O número 
de codificados em relação ao total de médicos que trabalhavam para o governo do estado então representava, portanto, 51,4\%. A maioria dos codificados eram homens e trabalhavam na macrorregião da Zona da Mata Paraibana (Tabela 1). Mais de um terço de todos os médicos codificados estavam cadastrados como clínicos, conforme ilustrado na Figura 1.

Durante o período avaliado, analisamos mês a mês o número de médicos que não permaneceram como codificados (identificamos esses médicos como "descodificados") e o número de novos médicos codificados. Como mostra a Tabela 2, o maior número de médicos descodificados foi observado na região da Zona da Mata (104). Entretanto, em números relativos, foi no Agreste onde ocorreu maior êxodo de profissionais em um ano (32\%). O número de novos codificados foi menor que o de descodificados. Como não houve concurso público no período avaliado, presumimos que houve diminuição da quantidade de médicos em postos de trabalhos das unidades gerenciadas pelo estado.

De acordo com Maciel e colaboradores ${ }^{21}$, a precarização do vínculo empregatício do médico com o Estado é danosa à saúde pública. $A$ instabilidade gerada pela ausência de contrato e pela supressão de direitos faz do médico um produto que a qualquer momento pode ser substituído, sem critérios técnicos, o que deixa o profissional à mercê da volição política do gestor. O elevado índice de descodificação verificado no presente estudo é mais uma demonstração da vulnerabilidade do médico nesses serviços.

$\mathrm{O}$ próprio Estado e as redes de assistência à saúde estão bem fragilizados nesse contexto, visto que a instabilidade empregatícia faz alguns médicos buscarem outros mercados, com formas legais de contratação. Saad, Saad e Branco ${ }^{22}$ relatam que a integração desse profissional nas rotinas dos serviços pode ser prejudicada pela rotatividade. Faz-se necessário, portanto, rever a vinculação dos profissionais dentro de um modelo que proporcione serviços de qualidade e uma relação de trabalho mais digna ${ }^{3}$.

A codificação como instrumento de contratação pode expor a população a risco, pois não se sabe quais são os critérios de admissão, sequer se os profissionais ditos especialistas possuem ou não habilitação e registro de qualificação de especialidade no CRM-PB. Não se pode aferir também qual o envolvimento desse profissional com a comunidade e com o sistema de saúde, considerando que não há vínculo empregatício e o desligamento do serviço público pode ocorrer a qualquer tempo. Isso é grave, pois inexiste sistema de saúde sem médico ${ }^{23}$.

Segundo Barchifontaine e Trindade ${ }^{24}$, é preciso valorizar a bioética no cotidiano, como parte importante da política de saúde. Para se alcançar uma assistência de qualidade, humanizada, capaz de garantir a dignidade da pessoa humana, é fundamental valorizar o trabalho do médico ${ }^{25}$.

Tabela 1. Número de médicos codificados e concursados e estratificação por gênero e mesorregião, segundo dados do Sistema de Acompanhamento da Gestão dos Recursos da Sociedade de novembro de 2019 (Paraíba)

\begin{tabular}{|c|c|c|c|}
\hline Médicos Codificados & Codificados N (\%) & Concursados N (\%) & $P^{*}$ \\
\hline \multicolumn{4}{|l|}{ GÊNERO } \\
\hline Feminino & $335(44,2)$ & $252(35,2)$ & 0,001 \\
\hline Masculino & $423(55,8)$ & $464(64,8)$ & - \\
\hline \multicolumn{4}{|l|}{ MESORREGIÃO } \\
\hline Zona da Mata Paraibana & $510(67,3)$ & $527(73,6)$ & 0,021 \\
\hline Borborema & $128(16,9)$ & $136(19)$ & - \\
\hline Agreste & $63(8,3)$ & $27(3,8)$ & - \\
\hline Sertão & $57(7,5)$ & $26(3,6)$ & - \\
\hline
\end{tabular}

continua... 
Tabela 1. Continuação

\begin{tabular}{|c|c|c|c|}
\hline Médicos Codificados & Codificados N (\%) & Concursados N (\%) & $P^{*}$ \\
\hline \multicolumn{4}{|l|}{ ESPECIALIDADE } \\
\hline Clínica & $261(34,4)$ & $230(32,1)$ & 0,078 \\
\hline Pediatria & $81(10,7)$ & $143(20)$ & - \\
\hline Anestesiologia & $76(10)$ & $23(3,2)$ & - \\
\hline Cirurgia Geral & $55(7,2)$ & $63(8,8)$ & - \\
\hline Ginecologia e Obstetrícia & $52(6,9)$ & $98(13,7)$ & - \\
\hline Medicina Intensiva & $48(6,3)$ & $32(4,5)$ & - \\
\hline Diagnóstico por Imagem & $32(4,2)$ & $39(5,4)$ & - \\
\hline Ortopedia e Traumatologia & $26(3,5)$ & $35(4,9)$ & - \\
\hline Outros & $127(16,8)$ & $53(7,4)$ & - \\
\hline Total & $758(100)$ & $716(100)$ & \\
\hline
\end{tabular}

* Teste de qui-quadrado.

Figura 1. Estratificação dos codificados de acordo com a especialidade, segundo dados do Sistema de Acompanhamento da Gestão dos Recursos da Sociedade de abril de 2019

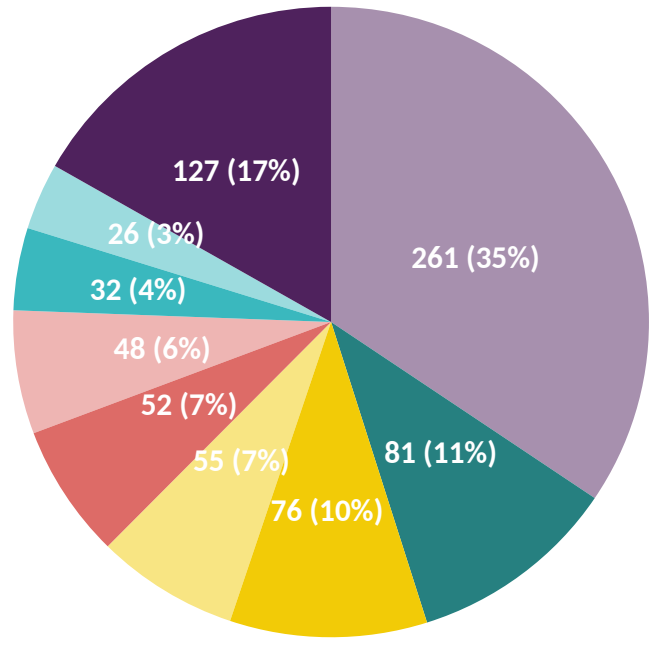

- CLÍNICO

- PEDIATRA

- ANESTESIOLOGISTA

CIRURGIÃO GERAL

- GINECOLOGISTA E OBSTETRA

- MEDICINA INTENSIVA

- RADIOLOGIA E DIAGNÓSTICO POR IMAGEM

- ORTOPEDISTA E TRAUMATOLOGISTA

- OUTROS

Tabela 2. Número de médicos descodificados e novos médicos codificados entre dezembro de 2018 e novembro de 2019, estratificados por macrorregião (Paraíba)

\begin{tabular}{lcc}
\multicolumn{1}{c}{ Médicos } & Frequência (N) & Porcentagem (\%) \\
\hline Zona da Mata Paraibana & 104 & 63,5 \\
Borborema & 32 & 19,5 \\
Agreste & 18 & 10,9 \\
Sertão & 10 & 6,1 \\
\hline Total & 164 & 100 \\
\hline
\end{tabular}

continua... 
Tabela 2. Continuação

\begin{tabular}{lcc}
\multicolumn{1}{c}{ Médicos } & Frequência (N) & Porcentagem (\%) \\
\hline Zona da Mata Paraibana & 74 & 56,5 \\
\hline Borborema & 30 & 22,9 \\
Agreste & 17 & 13 \\
Sertão & 10 & 7,6 \\
\hline Total & 131 & 100 \\
\hline
\end{tabular}

\section{Considerações finais}

É flagrante que no estado da Paraíba os direitos do médico, como cidadão, vêm sendo afrontados. Esses profissionais estão sujeitos à precarização causada por expedientes dolosos que visam mascarar a relação de trabalho com modalidades de contratação incertas e atípicas.

A modalidade de codificação é uma verdadeira ofensa ao ordenamento jurídico pátrio, já que nela a publicidade dos atos da administração é deficitária e insegura. Todos os direitos trabalhistas dos servidores - sejam eles celetistas ou estatutários, ou até mesmo contratados por tempo determinado - são negados aos codificados, não existindo contrato firmado entre o ente público e o cidadão contratado. Além disso, há suspeitas de irregularidade na utilização de verbas para quitar despesas com esse pessoal.

A codificação fere princípios constitucionais dos direitos sociais, da administração pública, da legalidade, da moralidade e da publicidade, confrontando ainda os princípios da equidade e da dignidade da pessoa humana. Os esforços dos órgãos de controle em nome da transparência não têm sido suficientes para resolver o problema. A contratação por codificação vem se perpetuando sem que o Estado apresente métodos de gestão para legalizar, à luz da Constituição Federal, o trabalho do médico nos serviços públicos estaduais. No entanto, é necessário resgatar o valor social dos médicos e da medicina, pois a precarização afeta a estabilidade dos trabaIhadores, a formação de vínculo com os usuários e indicadores de qualidade dos serviços de saúde, indo contra a própria dignidade da pessoa humana.

\section{Referências}

1. Organização da Nações Unidas. Declaração Universal dos Direitos Humanos [Internet]. Paris: Unesco; 1948 [acesso 11 mar 2021]. Disponível: https://bit.ly/33tJhMS

2. Brasil. Constituição da República Federativa do Brasil. Brasília: Senado Federal; 1988.

3. Girardi SN, Carvalho CL, Girardi LG. Modalidades de contratação e remuneração do trabalho médico: os conceitos e evidências internacionais [Internet]. 2007 [acesso 11 mar 2021]. Disponível: https://bit.ly/3evpi6L

4. Sousa JM, Lima LPN, Sousa ECM, Oliveira OR, Oliveira LC. Precarização dos serviços de saúde e suas implicações no processo de trabalho em saúde na atenção primária à saúde em Fortaleza. In: Silvestre LPF, editores. Políticas públicas no Brasil: exploração e diagnóstico 5 [Internet]. Ponta Grossa: Atena; 2018 [acesso 11 mar 2021]. DOI: 10.22533/at.ed.63619220118

5. Silva OP. Subordinação, autonomia e parassubordinação nas relações de trabalho. São Paulo: LTr; 2004.

6. Resende R. Direito do trabalho esquematizado. Rio de Janeiro: Método; 2011.

7. Rodrigues JRS. A caracterização da relação de emprego do médico na sociedade contemporânea. publicaDireito [Internet]. 2012 [acesso 11 mar 2021]. Disponível: https://bit.ly/3ewau7P

8. Barros AM. Trabalhadores intelectuais. Revista do Tribunal Regional do Trabalho da $3^{\text {a }}$ Região [Internet]. 2004 [acesso 11 mar 2021];39(69):147-65. Disponível: https://bit.ly/2PZLz2Y 
9. Brasil. Lei $n^{\circ} 8.745$, de 9 de dezembro de 1993. Dispõe sobre a contratação por tempo determinado para atender a necessidade temporária de excepcional interesse público, nos termos do inciso IX do art. 37 da Constituição Federal, e dá outras providências. Diário Oficial da União [Internet]. Brasília, 10 dez 1993 [acesso 9 mar 2021]. Disponível: https://bit.ly/3hchad9

10. Tribunal Superior do Trabalho. Súmula 363/TST [Internet]. 2000 [acesso 9 mar 2021]. Disponível: https://bit.ly/3hbrC4s

11. Instituto Brasileiro de Geografia e Estatística. IBGE | Cidades@ | Paraíba | Panorama [Internet]. Rio de Janeiro: IBGE; 2018 [acesso 20 jun 2019]. Disponível: https://bit.ly/2QWvHPv

12. Organização Mundial da Saúde. Spotlight: estatísticas da força de trabalho em saúde [Internet]. 2009 [acesso 13 jun 2019]. Disponível: https://bit.ly/2RwP957

13. Conselho Estadual de Saúde do Estado da Paraíba. Plano Estadual de Saúde 2016-2019: Resolução nº 0123 [Internet]. 2016 [acesso 10 jun 2019]. Disponível: https://bit.ly/2TpualK

14. Souto Maior S. TCE faz varredura na folha de codificados do governo e vai expor salários. Jornal da Paraíba [Internet]. 2017 [acesso 12 jun 2019]. Disponível: https://bit.ly/3vT5noc

15. Tribunal de Contas do Estado da Paraíba. Sistema de Acompanhamento da Gestão dos Recursos da Sociedade: Lista de médicos efetivos e codificados do Estado da Paraíba [Internet]. 2019 [acesso 10 jun 2019]. Disponível: https://bit.ly/3ew2uUs

16. Marinela F. Direito administrativo. $8^{\text {a }}$ ed. Niterói: Impetus; 2014.

17. Ministério Público Federal. Portaria $\mathrm{N}^{\circ} 23$, de $1^{\circ}$ de março de 2018. Procedimento Preparatório $\mathrm{n}^{\circ}$ 1.24.000.001214/2017-62. Diário do Ministério Público Federal Eletrônico [Internet]. Brasília, $n^{\circ} 47$, p. 58, 11 nov 2018 [acesso 10 jun 2019]. Disponível: https://bit.ly/3xZNG7Y

18. Brasil. Lei $n^{\circ} 8.112$, de 11 de dezembro de 1990. Dispõe sobre o regime jurídico dos servidores públicos civis da União, das autarquias e das fundações públicas federais. Diário Oficial da União [Internet]. Brasília, 19 abr 1991 [acesso 19 jun 2019]. Disponível: https://bit.ly/3bkty6Q

19. Brasil. Lei Complementar $n^{\circ} 101$, de 4 de maio de 2000. Estabelece normas de finanças públicas voltadas para a responsabilidade na gestão fiscal e dá outras providências. Diário Oficial da União [Internet]. Brasília, 5 maio 2000 [acesso 19 jun 2019]. Disponível: https://bit.ly/3vPS9Zc

20. Conselho Nacional de Saúde. Resolução $n^{\circ}$ 466, de 12 de dezembro de 2012. Aprova as diretrizes e normas regulamentadoras de pesquisas envolvendo seres humanos. Diário Oficial da União [Internet]. Brasília, p. 59, 13 jun 2013 [acesso 3 mar 2021]. Disponível: https://bit.ly/3o3sU34

21. Maciel RH, Santos JBF, Sales TB, Alves MAA, Luna AP, Feitosa LB. Multiplicidade de vínculos de médicos no Estado do Ceará. Rev Saúde Pública [Internet]. 2010 [acesso 3 mar 2021];44(5):950-6. DOI: 10.1590/ S0034-89102010005000030

22. Saad EG, Saad JED, Branco AMSC. CLT comentada Saad. 48ª ed. São Paulo: LTr; 2015.

23. Scheffer M, editor. Demografia Médica no Brasil 2020. São Paulo: Departamento de Medicina Preventiva da Faculdade de Medicina da USP, 2020.

24. Barchifontaine CP, Trindade MA. Bioética, saúde e realidade brasileira. Rev. bioét (Impr.). [Internet]. 2019 [acesso 3 mar 2021];27(3):439-45. DOI: 10.1590/1983-80422019273327

25. Santos IL. Igualdade, equidade e justiça na saúde à luz da bioética. Rev. bioét (Impr.). [Internet]. 2020 [acesso 21 abr 2021];28(2):229-38. DOI: 10.1590/1983-80422020282384 
Bruno Leandro de Souza - Doutorando - drbrunoleandro@yahoo.com.br (D) 0000-0002-1699-2986

Thiago Guimarães Pereira Souza - Graduado - thiagogjsouza@gmail.com (i) 0000-0003-2059-8356

Caio Chaves de Holanda Limeira - Graduado - caiolimeira@yahoo.com.br (i) 0000-0002-9365-6820

Heloísa Calegari Borges - Graduada - heloisacalegarib@gmail.com (D) $0000-0002-8026-262 X$

Naraiana Chaves Pereira - Graduada - naraianachaves@gmail.com

(D) 0000-0003-1407-3940

\section{Correspondência}

Bruno Leandro de Souza - Av. Dom Pedro II, 1335, Torre CEP 58040-440. João Pessoa/PB.

\section{Participação dos autores}

Bruno Leandro de Souza, Thiago Guimarães Pereira Souza e Caio Chaves de Holanda Limeira realizaram a revisão bibliográfica e coletaram os dados. Heloísa Calegari Borges e Naraiana Chaves Pereira participaram da análise estatística e da revisão crítica dos resultados. Todos os autores 